\title{
Probability of occurrence of planetary ionosphere storms associated with the magnetosphere disturbance storm time events
}

\author{
T. L. Gulyaeva ${ }^{1}$, F. Arikan ${ }^{2}$, and I. Stanislawska ${ }^{3}$ \\ ${ }^{1}$ IZMIRAN, Kaluzskoe Sh. 4, Troitsk, Moscow, 142190, Russia \\ ${ }^{2}$ Department of EEE, Hacettepe University, Beytepe, Ankara 06800, Turkey \\ ${ }^{3}$ Space Research Center, PAS, Barticka 18-A, Warsaw, Poland \\ Correspondence to: T. L. Gulyaeva (gulyaeva@izmiran.ru)
}

Received: 11 December 2013 - Revised: 31 January 2014 - Accepted: 18 February 2014 - Published: 11 November 2014

\section{Dedicated to 100 years of Professor Karl Rawer.}

\begin{abstract}
The ionospheric $W$ index allows to distinguish state of the ionosphere and plasmasphere from quiet conditions $(W=0$ or \pm 1$)$ to intense storm $(W= \pm 4)$ ranging the plasma density enhancements (positive phase) or plasma density depletions (negative phase) regarding the quiet ionosphere. The global $W$ index maps are produced for a period 1999-2014 from Global Ionospheric Maps of Total Electron Content, GIM-TEC, designed by Jet Propulson Laboratory, converted from geographic frame $\left(-87.5: 2.5: 87.5^{\circ}\right.$ in latitude, $-180: 5: 180^{\circ}$ in longitude) to geomagnetic frame $\left(-85: 5: 85^{\circ}\right.$ in magnetic latitude, $-180: 5: 180^{\circ}$ in magnetic longitude). The probability of occurrence of planetary ionosphere storm during the magnetic disturbance storm time, Dst, event is evaluated with the superposed epoch analysis for 77 intense storms (Dst $\leq-100 \mathrm{nT}$ ) and 230 moderate storms $(-100<\mathrm{Dst} \leq-50 \mathrm{nT})$ with start time, $t_{0}$, defined at Dst storm main phase onset. It is found that the intensity of negative storm, $i W^{-}$, exceeds the intensity of positive storm, $i W^{+}$, by 1.5-2 times. An empirical formula of $i W^{+}$and $i W^{-}$in terms of peak Dst is deduced exhibiting an opposite trends of relation of intensity of ionosphere-plasmasphere storm with regard to intensity of Dst storm.
\end{abstract}

\section{Introduction}

Ionosphere affects radio systems due to its temporally and spatially varying and dispersive nature. Online, near realtime estimates of ionospheric variability have increased importance in prediction of both high frequency (HF) commu- nication links and satellite based positioning and navigation systems. Global Ionospheric Maps of Total Electron Content (GIM-TEC) are cost-effective and user friendly means in observation of global distribution of TEC. A recently developed ionospheric $W$ index proved itself a versatile tool in distinguishing the ionospheric and plasmaspheric variability state, and thus identifying the stages and intensity of ionosphere storms (Gulyaeva and Stanislawska, 2008, 2010; Gulyaeva et al., 2011, 2013). The computation of $W$ index is based on GIM-TEC and its value can range from quiet state $(-1 \leq W \leq+1)$ to moderate storm $(W= \pm 3)$ and intense storm $(W= \pm 4)$. An increase and a depletion in electron density and total electron content relative to a background level are observed during storms and are called "positive" and "negative" phases of the storm, respectively. The positive $W$ index indicates plasma density enhancements and thus positive phase of an ionosphere storm. The negative $W$ index points to plasma density depletions during the negative phase of an ionosphere storm.

The characteristic storm-time patterns and processes in the Earth's ionosphere and plasmasphere are the subject of many years of theoretical and experimental studies (Obayashi, 1964; Kane, 1973; Prölls, 1995; Rawer et al., 2003; Mendillo, 2006; Jakowski et al., 2006, 2008; Biqiang et al., 2007; Gulyaeva and Stanislawska, 2010; Liu et al., 2010; Gillies et al., 2011; Gulyaeva and Veselovsky, 2012; Mukhtarov et al., 2013; Danilov, 2013). The solar wind is now generally accepted to be the cause of geomagnetic activity, auroral activity and particle intensity variations within the radiation belts. While much of the solar wind energy passes into auroral and polar cap regions, a considerable part of it is 
trapped and stored by the magnetosphere, plasmasphere and ionosphere.

In this paper the statistical study has been performed to analyze the relation of the probability of occurrence of the positive and negative ionosphere $W$ index storm with geomagnetic storms identified with the disturbance storm time, Dst, index (Sugiura and Kamei, 1991). The Dst index is taken as an indicator of Sun's induced geomagnetic disturbed conditions, as it represents the depressions in the ring current as a result of its interaction with the plasma signatures having their roots originated at the solar surface (Gonzalez et al., 1994). As distinct from investigations of the local effects and regional features of the ionosphere storms, this study is focused on global evaluation of probability of the ionosphere storm development as a part of the chain of storm propagation from the Sun to the solar wind, magnetosphere, plasmasphere and ionosphere extending the studies carried out so far with different approaches (Kane, 1973; Lal, 1997; Zhao et al., 2007; Liu et al., 2010; Gillies et al., 2011; Gulyaeva and Veselovsky, 2012; Mukhtarov et al., 2013).

\section{Data processing}

The degree of the equatorial magnetic field deviation is given by the Dst index representing the hourly average of the deviation of $\mathrm{H}$ (horizontal) component of the magnetic field measured by several ground stations around the world in mid- to low-latitudes. We have analyzed the events represented by maximum Dst decrease according to thresholds of $-100<\mathrm{Dst} \leq-50 \mathrm{nT}$ which mean moderate magnetic storm and Dst $\leq-100 \mathrm{nT}$ for an intense magnetic storm (Loewe and Prölss, 1997). Our Catalogue of Dst storms for the period of available Dst index since 1957 up to date is composed automatically from Dst index provided by the World Data Center for Geomagnetism, Kyoto, Japan, according to the following scenario.

The computer code for selecting both moderate and intense Dst storms is running through daily-hourly Dst data until it finds occurrence of Dstmin $\leq-50 \mathrm{nT}$. When double or multiple peaks of Dst occurs, the program selects $\min ($ Dstmin) for the total period. Then backward check through Dst array (starting back from Dst peak) is made looking for the onset $t_{0}$ of the main phase of storm until Dst is kept less than a threshold of Dst $\leq-30 \mathrm{nT}$. The forward check through the Dst array from Dstmin continues until Dst is less than the threshold of Dst $\leq-30 \mathrm{nT}$. More formal definition of Dst storm onset, initial phase, main phase and recovery phase are given by Veselovsky and Lukashenko (2013) but our criteria allow capture the main profile of Dst storm and study the $W$-index response to it.

A list of magnetic storms is compiled for this study for the period 1999-2012 of the solar cycles 23-24 when the routine production of numerical GPS-derived global ionospheric maps of the vertical total electron content, GIM-TEC, is car- ried out by the different Data Analysis Centers (Manucci et al., 1998; Hernandez-Pajares et al., 2009).

The Jet Propulson Laboratory (JPL) has created global ionospheric maps GIM-TEC of the total electron content at sub-hourly intervals (Manucci et al., 1998) provided on World Wide Web with a two-hour UT time resolution for 1998-2007 and sub-hourly resolution since 2008 onwards using a continually operating global network of Global Positioning System (GPS) receivers. To follow Dst data of $1 \mathrm{~h}$ UT resolution, JPL GIM-TEC maps for 1999-2012 are interpolated to one hourly UT TEC maps. Typically, GIMTEC maps are produced in IONEX format with $2.5^{\circ} \times 5^{\circ}$ resolution in latitude and longitude, respectively. Thus, each map in IONEX format consists of 5112 grid points in Earthfixed reference frame with geographic longitude ranging from $-180^{\circ}$ to $180^{\circ}\left(5^{\circ}\right.$ resolution $)$ and latitude from $-87.5^{\circ}$ to $87.5^{\circ}$ ( $2.5^{\circ}$ resolution). However, the ionosphere is sensitive to dynamic forces such as the neutral wind and electric field and its configuration depends on the magnetic field forcing the electrons along the magnetic field lines. For this study, JPL GIM-TEC maps for 1999-2012 are rearranged from geographic frame to geomagnetic coordinate system $\left(-85: 5: 85^{\circ}\right.$ in magnetic latitude, $-180: 5: 180^{\circ}$ in magnetic longitude).

$W$ index as a measure of the ionosphere-plasmasphere state is generated at each grid point of geomagnetic coordinates map with relevant thresholds for logarithmic deviation of TEC from 7 days running median of the type: DTEC $=\log$ (TECobs/TECmed) (Gulyaeva et al., 2013). The positive sign of DTEC refers to TEC enhancement, the negative sign to depletion. Term TECobs means observed TEC and TECmed means median TEC at a given hour UT. TECmed is sliding median for 7 days backward assigned to the last day of the window, i.e. for the 7th day. Such succession of backward days is applied for $W$ index assessment to be suitable for forecasting purposes. The 7 days window is selected because it smoothes (ignores) 27 days TEC oscillation due to solar rotation, 13.5 days and 9 days periods of recurrent geomagnetic activity oscillations. With the 7 days median, the hourly $W$ index allows to remove regular diurnal, seasonal and solar cycle TEC variability similar to 15 days backward median (Muchtarov et al., 2013). Criteria for selection of quiet ionosphere reference might be affected by data corresponding to magnetically disturbed conditions (Deminov et al., 2013). The 7 days backwards median is particularly suitable for the present study by selecting the events for which the pre-storm 7 days median is not affected by the magnetically disturbed conditions. With a system of adopted thresholds for DTEC (Gulyaeva et al., 2013) the magnitude of $W$ index varies from $W=0$ or \pm 1 for the quiet state to $W= \pm 2$ for the moderate disturbance, $W= \pm 3$ for the moderate ionospheric storm, and $W= \pm 4$ for the intense ionospheric storm. In the present study the map cells under positive storm conditions ( $W=3$ and 4 ) and negative storm conditions ( $W=-3$ and -4$)$ are identified for each hourly UT 
map, each day and month during 1999-2012 from $W$ index maps in magnetic coordinates. These storm $W$ index evaluations are compared with the magnetospheric storm events specified by the ring current Dst index.

We identify 77 intense magnetic storms (Dst $\leq-100 \mathrm{nT}$ ) and 227 moderate storms $(-100<\mathrm{Dst} \leq-50 \mathrm{nT})$ from Dst storms Catalogue for a period of 1999-2012. The superposed epoch analysis is performed by defining the start time of the epoch, $t_{0}$, at the onset of the main phase of Dst storm with Dst $\leq-30 \mathrm{nT}$, and extracting variation of Dst index and stormy $W$ indices during the main phase and the recovery phase of Dst storm. Probability of occurrence, $p W^{+}$, of the positive phase of ionosphere storm (number of $W=3$ and $W=4$ per map) and the negative phase, $p W^{-}$(number of $W=-3$ and $W=-4$ per map) relative to the total number of grids on a map is calculated in hourly-daily regime. Interrelation of probability of $p W^{+}$and $p W^{-}$with extreme Dst index is investigated and results are provided in the following section.

\section{Results}

The instantaneous global ionospheric map of total electron content, GIM-TEC, in magnetic coordinates frame is shown in Fig. 1a, and Fig. 1b presents the $W$ index map produced from it. The maps are divided symbolically by white lines to magnetic equatorial zone $\left(-15: 15^{\circ}\right)$, low latitude zone surrounding the peaks of the equatorial anomaly, EA $\left(-40:-15^{\circ} ; 15: 40^{\circ}\right)$, mid-latitude zone $\left(-60:-40^{\circ}\right.$; $\left.40: 60^{\circ}\right)$, and high latitude zone $\left(-90:-60^{\circ} ; 60: 90^{\circ}\right)$. Figure 1 demonstrates TEC and $W$ index maps for the peak of Dst $=-335 \mathrm{nT}$ occurred during the Halloween superstorm on 30 October 2003 at 2 h UT (see Fig. 2c). The clear asymmetry of TEC around the crests of EA is seen in the North and South magnetic hemispheres with enhanced electron content in the Northern magnetic Hemisphere (Fig. 1a). The crests of EA are observed at the geographic coordinates, local times and the solar zenith angle, $\chi:\left[24^{\circ} \mathrm{N}\right.$, $\left.208^{\circ} \mathrm{E}\right], 15.9 \mathrm{~h} \mathrm{LT}, \chi=71^{\circ}$ at the North, and $\left[19^{\circ} \mathrm{S}, 220^{\circ} \mathrm{E}\right]$, 16.7 hLT, $\chi=71^{\circ}$ at the Southern magnetic Hemisphere. One could not expect an asymmetry of the TEC EA structure under normal solar EUV radiation which is the same at the equal solar zenith angle $\chi$ at the both crests of EA over the Pacific Ocean. So we assume that Fig. 1a reproduces TEC asymmetry induced by the super-storm conditions. This assumption is confirmed further in discussion of Fig. 2.

It is obvious that the TEC map itself (Fig. 1a) is not capable to identify locations and degree of TEC perturbations but these are well identified with $W$ index map (Fig. 1b). Here we see symmetric positive storm areas $(W=4)$ in the North and South magnetic conjugate hemispheres during afternoon at low mid-latitudes and by nighttime hours at sub-auroral zones. The negative storm phase is specific to the South equatorial region and near-symmetric for the both hemispheres at
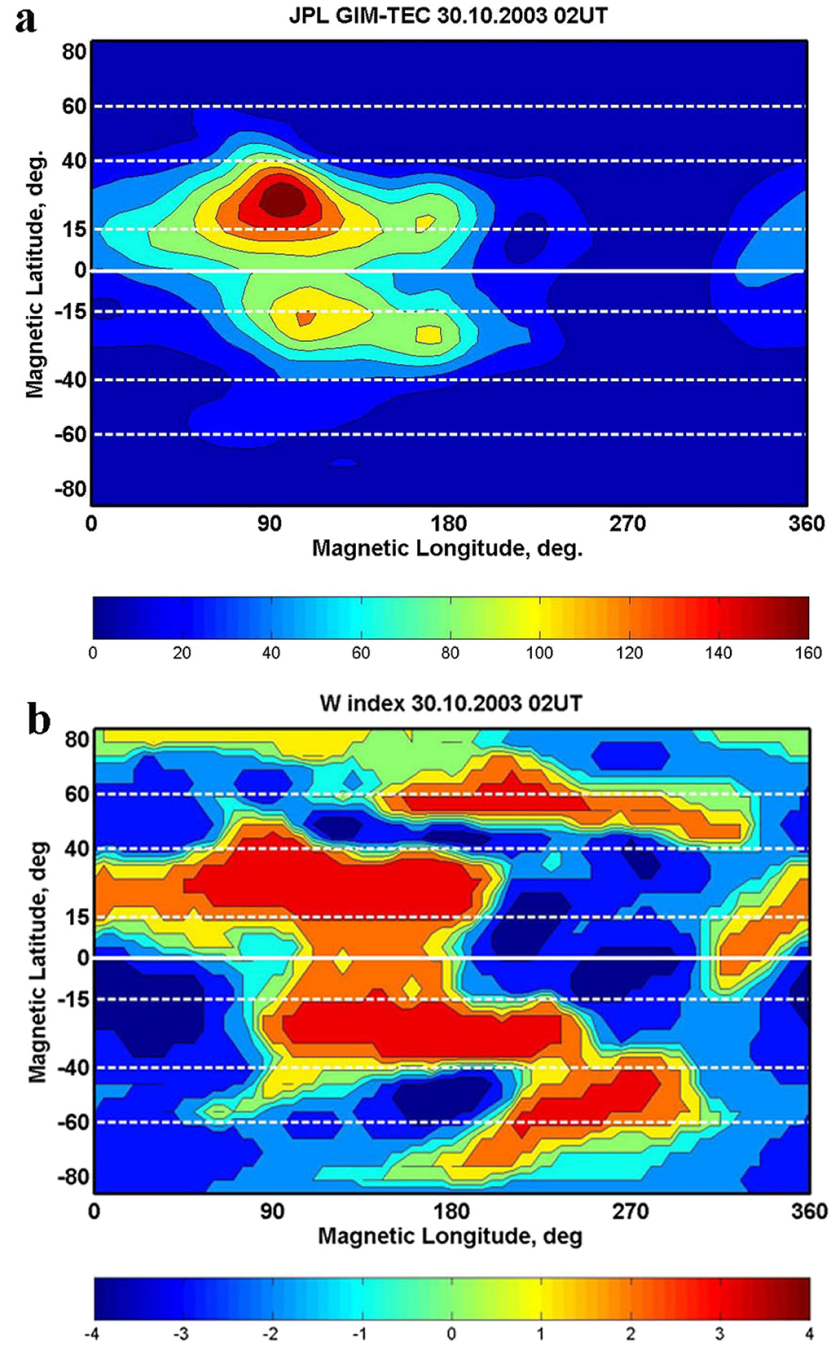

Figure 1. (a) Global ionospheric map of total electron content, GIM-TEC, and (b) $W$ index map, the both in magnetic coordinates frame, for the peak of Dst $=-335 \mathrm{nT}$ at the Halloween super-storm 30 October 2003, $02 \mathrm{~h} \mathrm{UT}$.

low latitudes towards nighttime. As concerns the magnetic conjugate regions which could be traced along the vertical magnetic meridian axes, the pattern of $W$ index storm appears to be inclined westward in the North hemisphere i.e. having onset of a particular phase of the storm earlier at the South magnetic hemisphere than at the North one.

Temporal development of TEC and $W$ index at the zero magnetic meridian passing the American continent is mapped in Fig. 2a, b during three days of the same Halloween super-storm shown by Dst index profile in Fig. 2c. The storm onset is 29 October 2003 at $7 \mathrm{~h} \mathrm{UT}\left(t_{0}=0\right)$, the first storm peak illustrated in Fig. 1, the second storm peak Dst $=-383 \mathrm{nT}$ observed 30 October 2003 at $22 \mathrm{~h}$ UT, and recovery on 01 November 2003 at $10 \mathrm{~h}$ UT. Outcome of the super-storm in erosion of TEC at EA peaks from day-today is evident from Fig. 2a which is particularly notable in 

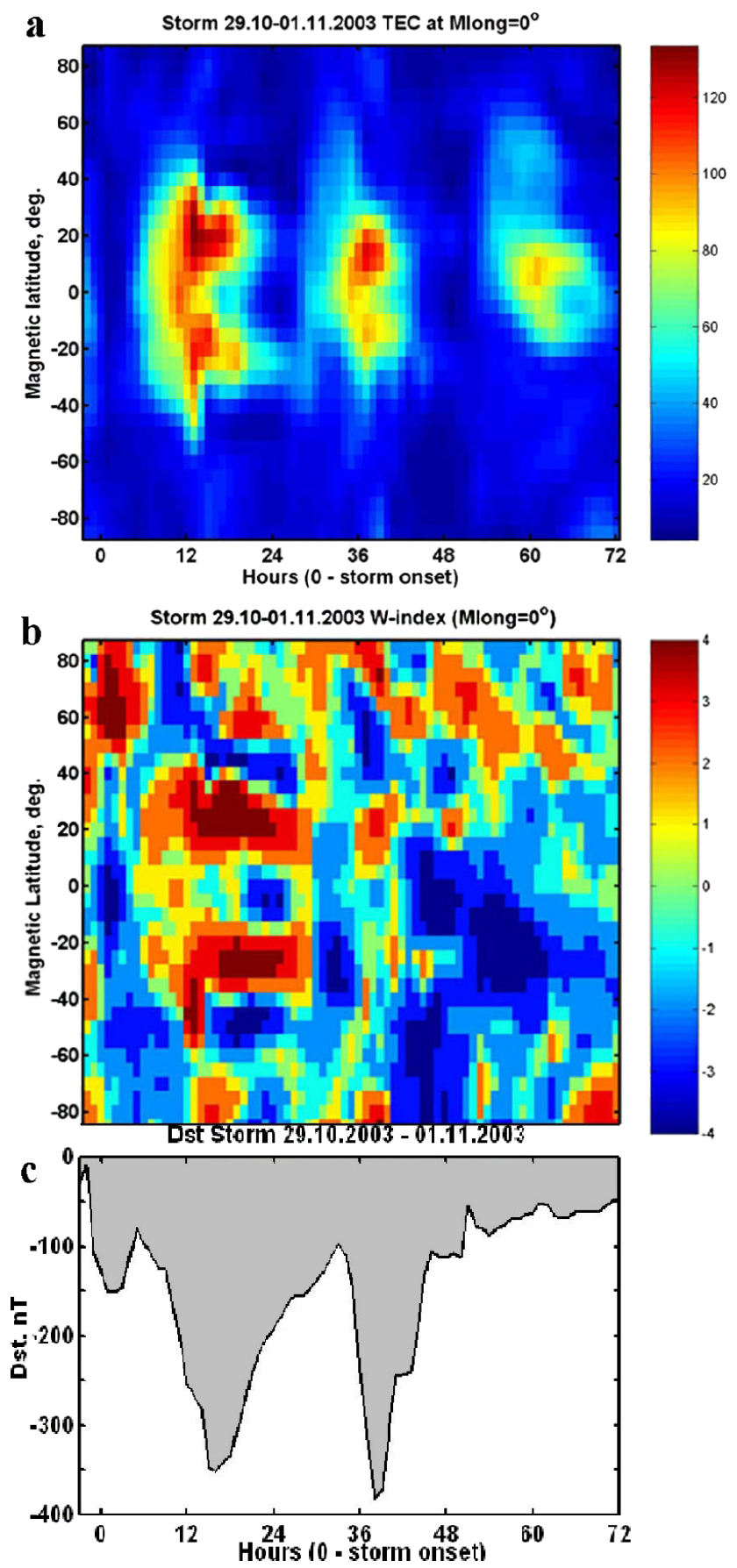

Figure 2. (a) Mapping TEC and (b) $W$ index along the zero magnetic meridian, and (c) Dst index during three days of the Halloween super-storm from 29 October $2003,07 \mathrm{~h} \mathrm{UT}\left(t_{0}=0\right)$ to recovery on 01 November 2003 at $10 \mathrm{~h} \mathrm{UT}$.

the Southern Hemisphere. The symmetry of positive $W$ in$\operatorname{dex}(W=3$ and 4$)$ at magnetic conjugate areas (Fig. $2 b)$ is well pronounced at low-latitudes during afternoon-to-night transition on 29 October followed by sporadic distribution of positive and negative storm patches at Northern and Southern Hemispheres. The prolonged negative $W$ index storm at low

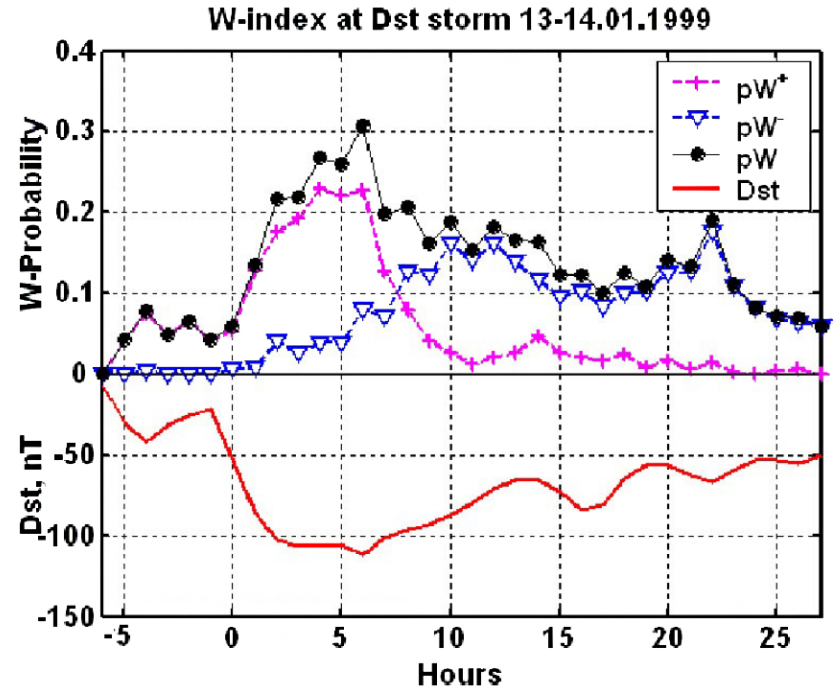

Figure 3. Variation of probability of positive $p W^{+}$and negative $p W^{-}$ionosphere storm and the total occurrence probability of stormy $W$ index, $p W$, (upper panel) and Dst storm profile (lower panel) from onset of the initial phase of storm 13 January $1999,11 \mathrm{~h}$ UT $(t=-6 \mathrm{~h})$, storm main phase onset 13 January 1999, $17 \mathrm{~h} \mathrm{UT}$ $\left(t_{0}=0\right)$ to 14 January $1999,20 \mathrm{~h}$ UT during the recovery phase.

latitudes in Southern magnetic Hemisphere on 31 October is depicted with almost full disappearance of TEC peak at the South crest of EA (Fig. 2a). Thus Figs. 1 and 2 demonstrate mutual complementarities of TEC map and $W$ index map in analysis of the ionosphere structure and dynamics particularly important for the ionosphere storm conditions.

We proceed to evaluation of probability of the positive and negative $W$ index storm signatures associated with Dst storm events. The probability $p W^{+}$and $p W^{-}$represents ratio of counts of $W=3$ and 4 and $W=-3$ and -4 to the total number of grids on a map ( $m=2520$ for the magnetic coordinates map). Total $W$ index storm probability per map is equal to $p W=p W^{+}+p W^{-}$.

Figure 3 presents results of probabilities evaluation for the Dst storm on 13-14 January 1999. The temporal axis starts at the onset of the initial phase of the storm at $t=-6 \mathrm{~h}$ corresponding to $11 \mathrm{~h}$ UT (Storm Sudden Commencement, SC, at 10:54 UT). The onset of the main phase, $t_{0}=0$, refers to 13 January $1999,17 \mathrm{~h} \mathrm{UT}$ and the plot is terminated at Dst partial recovery on 14 January 1999 at $20 \mathrm{~h} \mathrm{UT}(t=27 \mathrm{~h})$. The $p W^{+}$and the total $\mathrm{pW}$ curve is a mirror reflection of Dst variation coincident in onset time and the peak occurrence. The onset of the negative phase $p W^{-}$is delayed by $5 \mathrm{~h}$ after the $p W^{+}$onset and peaks $5 \mathrm{~h}$ later than Dst peak. This is an example of an intense Dst storm with slow initial and main phase lasting for $11 \mathrm{~h}$.

The general trends of intensity of the ionosphere storms can be deduced by comparing peak $p W^{+}$and $p W^{-}$variation against the peak reached by Dst index during the intense 


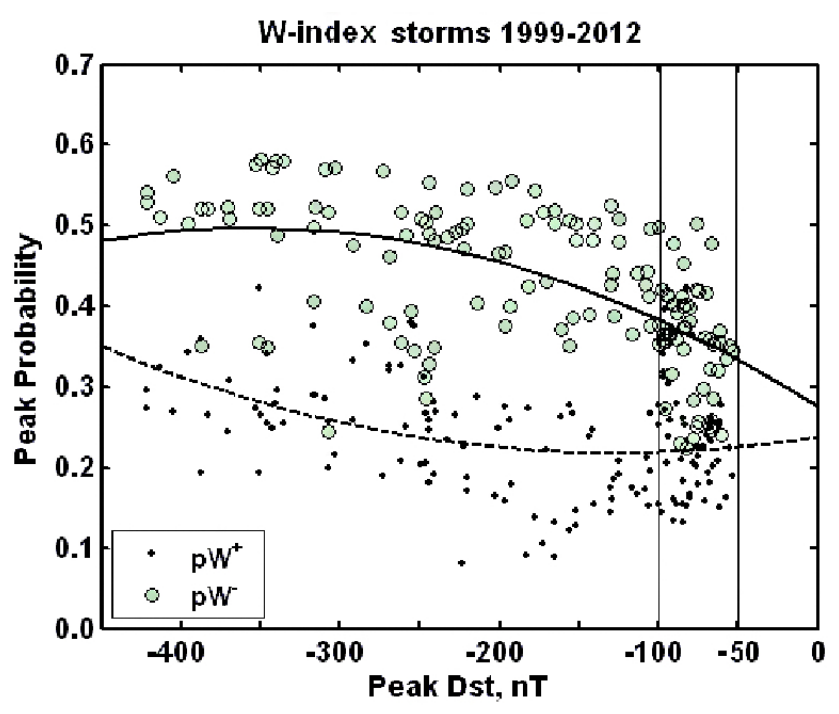

Figure 4. Intensity of positive and negative ionosphere storms versus peak of Dst storm and their fitting curves combined for more than 300 intense and moderate Dst storms during 1999-2012.

storms (panel on Fig. 4 located left of the vertical line at Dst $=-100 \mathrm{nT}$ ) and moderate storms (panel for Dst from -100 to $-50 \mathrm{nT}$ ). The least square approximation for the positive storm intensity $i W^{+}=\max \left(p W^{+}\right)$, and the negative storm intensity $i W^{-}=\max \left(p W^{-}\right)$versus peak Dst index, parameterized by $x=\min (\mathrm{Dst}) / 100$, for the combined intense and moderate storms is expressed by Eq. (1a)-(1b):

$i W^{+}=0.0126 x^{2}+0.0323 x+0.2392$

$i W^{-}=-0.0177 x^{2}-0.1253 x+0.2752$

The fitting curve for $i W^{+}$(Eq. 1a) is plotted by dashed curve and for $i W^{-}$(Eq. 1b) by solid curve in Fig. 4. It is evident from Fig. 4 that the peak probability of the negative storm, $i W^{-}$, exceeds the intensity of positive storm, $i W^{+}$, by $1.5-2$ times. This means that at the peak occurrence of negative $W$ index storm up to $50 \%$ of the total Earth's surface is under negative TEC depletion while only $20-30 \%$ of the Earth's surface can be reached under the enhanced TEC conditions.

\section{Conclusions}

In this work we address relation of probability of the positive and negative ionosphere global storm characterized by the ionospheric $W$ index with the magnetosphere storm evaluated with the disturbance storm time, Dst, index. $W$ index maps are produced from JPL global ionosphere maps of total electron content, GIM-TEC, for 1999-2012. The intense magnetosphere-ionosphere storms (77 events with Dst $\leq-100 \mathrm{nT}$ ) and 232 moderate storms $(-100<$ Dst $\leq-50 \mathrm{nT})$ were selected for this period of time. The superposed epoch analysis is performed for the Dst storms and probability of the positive ionosphere storms $\left(W^{+}=3\right.$ and 4$)$ and negative ionosphere storms $\left(W^{-}=-3\right.$ and -4$)$. The start time, $t_{0}$, of the superposed epoch is put at Dst storm main phase onset. Peak values of Dst index for the both categories of storms and intensity of the ionosphere storms $\left(i W^{+}\right.$and $\left.i W^{-}\right)$serve as a base for deducing an empirical analytical expression relating these parameters.

It is found that the Earth's area at the peak of the negative ionosphere storm conditions is 1.5-2 times greater than that for the positive ionosphere storm. An empirical expression is obtained for intensity of positive and negative ionosphere storm, $i W^{+}$and $i W^{-}$, in terms of peak Dst exhibiting an opposite trends of relation of positive and negative storm peak probability with regard to intensity of Dst storm. These results suggest a prospect for the more extended model of probability of the ionosphere storm to be deduced from the profile and intensity of the magnetosphere storm characterized by the disturbance storm time Dst index.

Acknowledgements. The GIM-TEC maps are provided by JPL at ftp://sideshow.jpl.nasa.gov/pub/. The Dst index is provided by WDC for Geomagnetism at http://wdc.kugi.kyoto-u.ac.jp/dstdir/index.html. The global $W$ index maps are provided at http://www.izmiran.ru/services/iweather/ and http://www.ionolab.org/. Catalogue of Dst storms is provided at http://www.izmiran.ru/services/iweather/storm/. This study is supported by the joint grant of TUBITAK 112E568 and RFBR 13-02-91370-CT_a. The authors thank the reviewers for their useful comments and suggestions.

Edited by: M. Förster

Reviewed by: L. Liu and one anonymous referee

\section{References}

Biqiang, Zhao, Weixing, Wan, Libo, Liu, and Tian, Mao: Morphology in the total electron content under geomagnetic disturbed conditions: results from global ionosphere maps, Ann. Geophys., 25, 1555-1568, doi:10.5194/angeo-25-1555-2007, 2007.

Danilov, A. D.: Ionospheric F region response to geomagnetic disturbances, Adv. Space Res., 52, 343-366, doi:10.1016/j.asr.2013.04.019, 2013.

Deminov, M. G., Deminova, G. F., Zherebtsov, G. A., and Polekh, N. M.: Statistical properties of variability of the quiet ionosphere F2-layer maximum parameters over Irkutsk under low solar activity. Adv. Space Res., 51, 702-711, doi:10.1016/j.asr.2012.09.037, 2013.

Gillies, D. M., McWilliams, K. A., St. Maurice, J.-P., and Milan, S. E.: Global-scale observations of ionospheric convection during geomagnetic storms, J. Geophys. Res., 116, A12238, doi:10.1029/2011JA017086, 2011.

Gonzalez, W. D., Joselyn, J. A., Kamide, Y., Kroehl, H. W., Rostoker, G., Tsurutani, B. T., and Vasyliunas, V. M.: What is geomagnetic storm?, J. Geophys. Res., 99, 5771-5792, 1994.

Gulyaeva, T. and Veselovsky, I. S.: Two-phase storm profile of global electron content in the ionosphere and plas- 
masphere of the earth, J. Geophys. Res., 117, A09325, doi:10.1029/2012JA018017, 2012.

Gulyaeva, T. L. and Stanislawska, I.: Derivation of a planetary ionospheric storm index, Ann. Geophys., 26, 2645-2648, doi:10.5194/angeo-26-2645-2008, 2008.

Gulyaeva, T. L. and Stanislawska, I.: Magnetosphere associated storms and autonomous storms in the ionosphereplasmasphere environment, J. Atmos. Sol.-Terr. Phy., 72, 90-96, doi:10.1016/j.jastp.2009.10.012, 2010.

Gulyaeva, T. L., Arikan, F., and Stanislawska, I.: Inter-hemispheric imaging of the ionosphere with the upgraded IRI-Plas model during the space weather storms, Earth Planets Space, 63, 929-939, doi:10.5047/eps.2011.04.007, 2011.

Gulyaeva, T. L., Arikan, F., Hernandez-Pajares, M., and Stanislawska, I.: GIM-TEC adaptive ionospheric weather assessment and forecast system, J. Atmos. Sol.-Terr. Phy., 102, 329-340, doi:10.1016/j.jastp.2013.06.011, 2013.

Hernandez-Pajares, M., Juan, J. M., Sanz, J., Garcia-Rigo, A., Feltens, J., Komjathy, A., Schaer, S. C., and Krankowski, A.: The IGS VTEC maps: A reliable source of ionospheric information since 1998, J. Geodesy, 83, 263-275, 2009.

Jakowski, N., Stankov, S. M., Schlueter, S., and Klaehn, D.: On developing a new ionospheric perturbation index for space weather operations, Adv. Space Res., 38, 2596-2600, doi:10.1016/j.asr.2005.07.043, 2006.

Jakowski, N., Mielich, J., Borries, C., Cander, L., Krankowski, A., Nava, B., and Stankov, S. M.: Large-scale ionospheric gradients over Europe observed in October 2003, J. Atmos. Sol-Terr. Phy., 70, 1894-1903, doi:10.1016/j.jastp.2008.03.020, 2008.

Kane, R. P.: Global evolution of F2-region storms, J. Atmos. Terr. Phys., 35, 1953-1966, 1973.

Lal, Ch.: Contribution to F2 layer ionization due to the solar wind, J. Atmos. Sol.-Terr. Phy., 59, 2203-2211, 1997.
Liu, J., Zhao, B., and Liu, L.: Time delay and duration of ionospheric total electron content responses to geomagnetic disturbances, Ann. Geophys., 28, 795-805, doi:10.5194/angeo-28795-2010, 2010.

Loewe, C. A. and Prölss, G. W.: Classification and mean behavior of magnetic storms, J. Geophys. Res., 102, 14209-14214, doi:10.1029/96JA04020, 1997.

Manucci, A. J., Wilson, B. D., Yuan, D. N., Ho, C. M., Lindqwister, U. J., and Runge, T. F.: A global mapping technique for GPSderived ionospheric total electron content measurements, Radio Sci., 33, 565-582, 1998.

Mendillo, M.: Storms in the ionosphere: patterns and processes for total electron content, Rev. Geophys., 47, RG2001, doi:10.1029/2005RG000193, 2006.

Mukhtarov, P., Andonov, B., and Pancheva, D.: Global empirical model of TEC response to geomagnetic activity, J. Geophys. Res.-Space, 118, 6666-6685, doi:10.1002/jgra.50576, 2013.

Obayashi, T.: Morphology of storms in the ionosphere, in Research in Geophysics, Vol. 1, edited by: Odishaw, H., 335-366, MIT Press, Cambridge, Mass., 1964.

Prölls, G.: Ionospheric F-region storms, Handbook of Atmospheric Electrodynamics, Vol. 2, edited by: Volland, H., Chap. 8, 195248, CRC Press, Boca Raton, Fla., 1995.

Rawer, K., Kouris, S. S., and Fotiadis, D.: Variability of F2 parameters depending on MODIP, Adv. Space Res., 31, 537-541, 2003.

Sugiura, M. and Kamei, T.: Equatorial Dst index 1957-1986, IAGA Bulletin, No. 40, 1991.

Veselovsky, I. S. and Lukashenko, A. T.: Statistics of isolated and complex geomagnetic storms based on the APEV database for cycle 23 of solar activity, Geomagn. Aeronomy, 53, 595-603, doi:10.1134/S0016793213050162, 2013. 